Journal of Development and Communication Studies, Vol. 6. No. 1, January - June 2019 ISSN (Online \& Print): 2305-7432.

http://www.devcomsjournalmw.org.

\title{
Mediated Political Participation and Competing Discourses of Online Civic Engagement
}

Philip Oburu Onguny, School of Social Communication, Saint Paul University, Ottawa, Canada. Email: ponguny@ustpaul.ca

\begin{abstract}
This article focuses on the interconnections between mediated political participation and online citizen engagement. The objective is threefold. First, it examines whether the notion of digital democracy captures the dynamic and "renewed" sense of civic responsibility brought to bear by disruptive information and communication technologies (ICTs). Second, it asks the question of whether the creation, negotiation, dissemination, and consumption of online political content really rivals those circulated by the traditional or legacy media. Finally, the article discusses the potential pitfalls of confining technological use patterns to pessimist-optimist dichotomy, arguing that such characterization ignores innovative or adapted use patterns that emerge based on varying social, political, and economic realities. Overall, the discussions presented in this article are meant to generate conceptual discussions around the links between mediated political participation and online civic engagement, and how they inform democratization processes and redistribution of political influence.
\end{abstract}

Keywords: Mediated politics, mediated political participation, digital democracy, mediated public sphere, ICTs, digital divide, online civic engagement, civic responsibility

https://dx.doi.org/10.4314/jdcs.v6i1.3

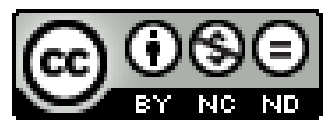

(C) 2019. The Author. This work is licensed under the Creative Commons Attribution 4.0 International License (CCBy-NC-ND). Users may freely share and redistribute this work provided that the author and the Journal of Development and Communication Studies are fully acknowledged. Users may not tweak or remix and offer this work for sale. The full license may be accessed at https://creativecommons.org/licenses/by-nc-nd/4.0/

\section{Introduction}

The past two decades have seen a steady increase in the number of people and political parties using online communication to achieve political objectives. One long-standing explanation for this has been that online communication offers interactive and participatory interfaces that alter the relationship between governments, organizations, and citizens (Bennett and Entman, 2000). Not only have such platforms become integral components of political campaigns; they have also "transform[ed] the way people live, work and play" (Norris, 2001, 1) while, at the same time, allowing ordinary citizens to transcend geographical and social barriers that once characterized conventional politics (Rice and Katz, 2004; Coleman, 2005). Accordingly, information and communication technologies (ICTs) have not only allowed for the emergence of participatory and inclusive forms of civic engagement (Benson, 2001; Bentivegna, 2006); they have also expanded the scope of political content to citizens compared to those offered by the so-called traditional or legacy media (Morris, 2002; Johnson and Kaye, 2003). 
Given the disruptive nature of these platforms, "new voices" have been brought into politics and "new" forms of civic engagement have emerged. It is this perceived democratization process supported by online communication tools that has loosely been labelled digital democracy.

However, these considerations are not shared by all. Critics of digital democracy contend that the potentials of online communication are proportionately harnessed by the dominant "classes" to strengthen their policy options and/or neutralize citizens' disaffection (Dalrymple and Scheufele, 2007). In fact, studies have shown that, while online communication tools such as blogs expand the scope of political participation, they are characterized by elite capture (Meraz, 2009; Astrom and Karlsson, 2013). Meraz (2009), for instance, argues that blogging has attracted a wide range of readers and writers who blur the boundaries of what was once considered as "public personal journalism". For Meraz, some independent bloggers have gone as far as gaining prominence and credibility at the expense of traditional media. This, according to her, questions the whole idea of "decentralized citizen control as opposed to hierarchical, elite control" (p. 682). She writes: "This form of Web content creation has matured beyond public personal journaling to support citizen journalism or journalism produced by independent bloggers unaffiliated with professional newsrooms" (p. 682). Similar views are expressed by Astrom and Karlsson (2013), who believe that, while "blogs are touted as having the potential to reinvigorate political communication by facilitating decentralization, individualization, and interactivity" (p. 436), they are increasingly "shaped by national institutional settings, that is, the different roles given to parties within political systems" (p. 434).

Consequently, in attempting to make sense of the changing media environment, some scholars have wondered why "rich media" environments still experience "poor democracy" (McChesney, 1999). This media-democracy paradox is believed to stem from a wide range of factors such as "hypercommercial" nature of media organizations, concentration of media systems within a handful of corporations, and influential roles played by the affluent population in determining news agenda (McChesney, 1999). Using concepts such as "news value" and media's "carrying capacity", some scholars have also resorted to determine what kinds of political message are likely to be circulated by the news media to increase public attention (Helfer and Van Aelst, 2016). Overall, these debates give rise to several interrelated questions: What "news value" do online communication platforms offer to the public? How are they likely to influence deliberative and representative democratic processes? What forms of citizen engagement do they give rise to and how?

Although it would be impossible to provide conclusive perspectives on these questions without conducting an empirical investigation, the questions proposed are meant to guide the discussions around the complex relationship between mediated political participation and discourses of online citizen engagement. As Hindman (2009) reminds us, "scholars [...] disagree about what precisely citizenship requires and what our definitions of political voice should therefore include. Yet proponent of participatory citizenship, deliberative citizenship, and monitorial citizenship all focus on political equality - and particularly on making formal political equality meaningful in practice" ( $p$. 8). It is unclear what forms of civic engagement emerge through online mediated political participation, as the literature is still inconclusive to this end.

Drawing on these discussions, this article focuses on the relationship between mediated forms of political participation and online citizen engagement. Since the primary objective of the article is to generate discussions around this complex relationship, the article starts by clarifying key concepts used to situate them within the broader conceptual framework. It then focuses on the pessimistoptimist debates that have dominated technological use and/or adoption. The third section brings to focus the links between mediated politics, digitally-mediated representation, and online citizen engagement. Finally, the last section reflects on the future of online civic engagement within the context of populism while, at the same time, discussing the emerging concerns over the use of online 
communication platforms by terrorist networks to recruit individuals based on the same principles of civic responsibility.

\section{Conceptual Clarifications}

In a more general sense, mediated politics refers to the "transformations in politics and public sphere that arise from the changing operations of new and old communication technologies" (Bennett and Entman, 2000, 3). Therefore, mediated political participation represents the shifts in the creation, negotiation, and dissemination of political content to incentivise online public participation. As others have noted, politicians and institutions increasingly use online communication tools to personalize and orient their messages in order to meet the varying demands of the public (Michailidou and Trenz, 2013). This is because people's political interests are more fragmented than ever before. Mediated political participation is, in this regard, understood as personalized, fragmented, and rapidly evolving forms of engagement with online media content. Certainly, politicians and/or political parties increasingly "professionalize" and "marketize" political content as a means to increase public participation and/or engagement in political processes (Michailidou and Trenz, 2013). As a consequence, the "quality, quantity and persuasiveness" of news are progressively called in question (Graber, 2004, 551). What is more, these transformations change what De Beus (2011) calls "marriage de raison” between journalists and politicians. He writes: “...journalists needed politicians for news about government and for information about what took place in the policy process; politicians needed journalists for news about society and for media exposure" (p. 19).

Another concept guiding this reflection is the notion of civic engagement, understood here as people's involvement in public affairs at the individual and collective levels (Park and Perry, 2008). Civic engagement, as used here, is closely related to Manin's (1997) idea of "audience democracy" (as opposed to "party democracy"). As Manin pointed out, one characteristic of "audience democracy" is the gradual "personalization of electoral choice". This is because "audience democracy" variably represents a rupture with traditional democratic values. Accordingly, online communication tools offer citizens the possibility of bypassing elected officials on certain instances, and, therefore, express political opinions and/or wishes more directly. This renders the notion of political representation more fluid, including "the consent of majority" often regarded a key aspect of representative democracies (Manin, 1997).

Closely linked to the notion of civic engagement is mediated public sphere, used here to underscore "a manufactured public sphere, in the sense that [...] editors have a central role in deciding what opinions actually reach print state, and furthermore, in the sense that an opinion that reaches print is also an edited opinion" (Bangstad, 2013, 360). At the core of this idea is the assumption that mediated public sphere gives rise to competition among news organizations, thereby resulting in centralized and fragmented forms of journalistic practice (Benson, 2001). In the process, the Habermacian view of public sphere initially aimed at "promot[ing] rational-critical public debate involving the widest possible citizen participation" is gradually transformed (Benson, 2001, 2). Other scholars such as Poor (2006) also argue that "issues of governance" once dominated by the "bourgeoisie" discourses are now extended to the general public.

The term democracy is used here in Graber's (2004) sense of the word, referring to "government controlled by the people" (p. 546). That is, it can be "direct, where people actually participate in town meetings or vote on referenda to make rules and laws and provide for their execution" or "indirect, where people elect representatives who act as their agents in making and executing laws that govern society" (p. 546). Building on this logic, digital democracy refers to "any electronic exchange of value in the democratic process" (Caldow, 1999, 2). However, given the broadness of the term, it is worth noting that the expounded benefits associated with the "electronic exchange of value" are increasingly questioned. In writing about the "myth of digital democracy" in the U.S., Hindman (2009), for instance, 
argues that "if we want to understand the fate of politics in the Internet age, we also need to acknowledge new and different types of exclusivity that shape online politics" (p. 4). In other words, the idea of digital democracy is problematic both at the normative (i.e. concerning issues of universality) and empirical (i.e. problems locating the main agency of change) levels. Empirically, "the hope has been that the Internet would expand the public sphere, broadening both the range of ideas discussed and the number of citizens allowed to participate" (Hindman, 2009: 7). In the recent past, studies on digital democracy have taken the form of "digital revolution" and/or the "Arab Spring" (Anderson, 2011; Earl and Kimport, 2011; Wolfsfeld, Segev and Sheafer, 2013; Aday et al., 2012). Such studies have also produced mixed results with regard to the propensity of digitally-mediated political participation to increase civic responsibility.

Finally, digital divide is understood here in Norris' (2001, 1) view, which highlight three interrelated aspects. These are: "the global divide" (i.e. "the divergence of Internet access between industrialized and developing societies"), the "social divide" (i.e. "the gap between information rich and poor in each nation"), and the "democratic divide" (i.e. "the difference between those who do, and do not, use the panoply of digital resources to engage, mobilize and participate in public life"). Overall, these concepts offer varying meanings with regard to issues of territoriality, political representation, and civic engagement.

\section{Mediated Politics and Debates over Technological Use/Adoption}

The impact that technology has on societal transformation has always been a subject of debate. One of the debates has involved discussions around technological optimism versus technological pessimism. Proponents of technological optimism often emphasize the promise that such artefacts have over potential risks and/or uncertainties (Marx, 1994; Krier and Gillette, 1985). As Krier and Gillette $(1985,409)$ put it, "the optimists believe in unending human ingenuity, or at least human ingenuity with no foreseeable limit. They must believe this, because human ingenuity is a necessary, though not a sufficient, condition of technological advance". In contrast, technological pessimism underscores a "sense of disappointment, anxiety, even menace, that the idea of 'technology' arouses in many people these days" (Marx, 1994, 238). The differences between pessimist and optimist views, therefore, lie in how individuals deal with risks.

Another line of argument regarding the use/adoption of technology has pinned discussions around information "haves" against information "have-nots". At the core of these debates is the negotiation around "digital divide" and issues of social inequality that accompany people's experience with information and communication technologies. In this regard, Wresch (1996) believes that the disparity between those connected to the "web" and the "disconnected" is rooted in the differences that people have with respect to information source, information dissemination, and information reception. Drawing on examples from Africa (Namibia), Wresch attributes such gaps to problems ranging from citizens' literacy level to regulatory and infrastructural challenges at the local and national levels. In a similar vein, some studies have confined the understanding of such disparities within "inforich"-"info-poor" dynamics, focusing primarily on the imbalances characterizing information access at the global level (Hayward, 1995).

Increasingly, however, a group of studies reject such dichotomous categorizations. For instance, earlier studies on the links between information technology and citizen engagement already "advocate[ed] rejecting the idea of a distinction between technology-related civic engagement and traditional civic engagement" Bimber (2000, 329). Other studies have also indicated that such categorization focuses uniquely on problems of information access, use, and distribution, without capturing the complexities surrounding people's experience with technology (Chen and Wellman, 2005). As a result, some scholars argue for the use of the term "digital inequality" instead, perceived as an integrative term that also includes "inequality among persons with formal access to the Internet" 
(DiMaggio and Hargittai, 2001, 1). This means that capturing the intricacies of digital inequality would require "...identifying critical dimensions of inequality; documenting differences among groups; explaining the antecedents of inequality on these dimensions; and modeling the relationship among different forms of inequality and between these and critical outcomes" (p. 7-8). The same view is expressed by Chen and Wellman (2005) who argue that different forms of social inequality associated with the Internet (e.g. "engaging in civic or entrepreneurial activities" p. 523) should be understood more broadly, rather than focusing on access and use.

In essence, these studies reveal the potential pitfall of taking a pessimist-optimist approach when explaining the difference between mediated political participation and online forms of civic engagement. Concretely, the pessimism-optimism debates and info-rich/info-poor views often draw on diffusion theory, which centres on the spread of technology-supported artefacts and how they are received (or not) in different settings (Karshenas and Stoneman, 1995). Further, such binary categorizations have received criticisms for being deterministic, as technological artefacts are either considered the primary agency of change or an impediment to the change process (Bimber, 2000). To put it another way, "the actual experience of a citizen with different modes of communication or information exchange may on some occasions tend to blur differences" (Bimber, 2000, 330). Building on this premise, some studies have started to focus on innovative use patterns of technological artefacts - uses that emerge depending on users' social, political, and economic realities (Van Deursen and Van Dijk, 2014; OECD, 2011/2015).

Ultimately, these realities inform people's adoption or rejection of the technology in question. This is why scholars such as Billon, Lera-Lopez and Marco (2017) believe that contemporary policies on technological adoption should consider the "combined patterns of ICT use" as a means to capture the entire potential of technological artefact at the local, national and global levels. In fact, Billon, Lera-Lopez and Marco (2017) argue that "further research should be carried out to analyze the effects of other potential variables, as well as to investigate whether innovation and ICT use might vary across different time periods" (p. 39).

Given these areas of debate, the views on technological use tilt online civic engagement toward what some call "civic cultures" or "civic identities" (Dahlgren, 2000; McKinney et al., 2005). Such "cultures" extend the notion of civic engagement beyond individual or collective voting patterns (Howard, 2005; Johnson 2006; Rice and Katz, 2004; Dalrymple and Scheufele, 2007). Understood in this sense, online citizen engagement is likely to depend on how politicians and their constituents harness these interactive platforms to increase the overall democratic experience beyond conventional democratic ideals such as political representation. This could encompass organizing demonstrations, volunteering in political processes, raising awareness on human rights issues, and bringing subaltern voices into the mainstream political discourse.

\section{Mediated Politics and Online Civic Engagement}

Norris $(2000,7)$ reminds us that political representation in liberal democracies often revolves around three normative benchmarks. That is, "pluralistic competition among parties and individuals for all positions of government power; participation among equal citizens in the selection of parties and representatives through free, fair and periodic elections; and, civil and political liberties to speak, publish, assemble, and organize, as necessary conditions to ensure effective competition and participation". The question that arises, however, is whether digitally-mediated politics provide the same conditions allowing online users to make informed decisions. Further, given the changing nature of civic engagement and the varying information needs of individuals, it is not quite clear what forms of civic activity they reinforce or weaken. The literature is still divided on the practical implications of such platforms, particularly when associated with increased sense of civic responsibility. 
To support this view, Norris $(2000,7)$ argues that, despite increased penetration of the Internet, "a substantial democratic divide may still exist between those who do and do not use the multiple political resources available on the Internet for civic engagement". In this sense, linking mediated politics with increased civic and/or political activity would require one to assume that "participants in direct or indirect democracy know enough about the situations with which they are dealing to make intelligent, rational decisions" (Graber, 2004, 546). This, of course, would be erroneous on many levels. First, this would mean that citizens acquire and process political content in the same way, which is less plausible. Second, such position ignores the professionalization and marketization of political content by various actors to meet fragmented needs of the public. In other words, such view would ignore mediated processes of content production, circulation and consumption. Finally, holding such a stance would mean bypassing the contexts within which digitally-mediated meaning is situated, and the valence attached to certain forms of civic responsibility over others. What, then, links mediated politics with certain forms of online citizen engagement? Any meaningful analysis of such links would of course require one to conduct research at the normative and/or empirical levels. Nevertheless, there is sizable literature on the topic that one can draw on to make some inferences.

Morris (2002), for instance, believes that citizens with access to online communication platforms are more likely to be involved in different sorts of democratic processes such as learning more about elected officials. This, according to the author, increases the interaction between elected officials and their constituents, thereby increasing people's sense of civic responsibility. Others also argue that internet-supported interfaces like blogs increasingly empower groups that were once perceived as "voiceless", and that elected officials increasingly pay attention to what they have to say; failure to which their re-election is compromised (Morris, 2002; McKinney et al., 2005; Hathornthwaite and Rice, 2006). A dominant explanation for this is that citizens are progressively disaffected by news circulated by the so-called "traditional media" (Johnson, 2006; McChesney, 1999; Morris, 2002; Moe, 2008). Online communication tools provide users with the means to produce and consume content depending on their varied interests (Tewksbury, 2006). This, in the process, may counter dominant political narratives.

Other studies have also argued that increased online presence (as a means of political participation) should not largely be attributed to the growing alienation towards political parties; instead, researchers should examine how such platforms give rise to "new forms" of democratic reengagement such as organizing public demonstrations, mobilizing voters against controversial policies, and participating in online polls (Bentivegna (2006). Put differently, individuals are gradually shifting their ways of civic engagement by redefining the contours of politics to meet their own interests (Howard, 2005; Johnson, 2006). Accordingly, such transformations have also led to the reconceptualization of public sphere, seen as "a form of deterritorialization [...], eliminating old boundaries and enabling the emergence of new forms of politics" (Bentivegna, 2006, 333). Put simply, new forms of civic responsibility could simply mean information acquisition to increase one's awareness around everyday life situations.

As Coleman (2005) warns, it would be a mistake to assume a deterministic relationship between "new technologies" and a more direct form of democratic representation. This is because institutional adaptation to procedural, political, and cultural challenges brought to bear by online communication is still gradual. In essence, Coleman believes there are three primary ways online communication is likely to increase civic engagement: "by enabling a more expansive and interactive kind of accountability to take place [...], by accommodating a pluralistic network of representations, in contrast to the singular, linear conception of political representation characteristic of analogue mediation, [and]...by creating new spaces of public self-representation and experimental reflexivity (Coleman, 2005, 190). 
Certainly, online communication platforms alone do not translate into increased civic activity and/or political involvement. It is widely documented that such platforms also strengthen the status quo (Dalrymple and Scheufele, 2007; Johnson, 2006). Even worse, they deepen the gap between dominant political rhetoric and "marginalized" or subaltern voices (Earl and Kimport, 2011; DiMaggio and Hargittai, 2001). Further, increase and diversification of political content online do not translate into increased civic engagement (Cammaerts and Van Audenhove, 2005). The decision to participate in political discussions relies upon individuals' interest in politics.

Further, online news consumers often blend both traditional media and online sources (Dalrymple and Scheufele, 2007), which points to the centrality of legacy media in political opinion formation. In this regard, the argument that online communication provides "new" or "alternative" pieces of information holds very little. Instead, it supplements the news gathered from traditional sources (Moe, 2008). Equally, research shows that those who use online tools for political reasons are individuals already active in "offline politics" with pre-established political preferences (Dahlgren, 2000; Johnson and Kaye, 2003; Howard, 2005). Building on this view, one would argue that people use online communication platforms to reinforce pre-existing beliefs or create new ones.

Finally, there are studies claiming that the ability to filter relevant online political content is subject to one's judgment and context-dependent factors (McKinney et al., 2005; Trammell et al., 2006; Tewksbury, 2006). Thus, eliminating the roles of "opinion leaders" in political content filtering or meaning generation could potentially lead to the consumption of ill-doctored content, particularly in today' society characterized by "fake news" phenomena (Allcott and Gentzkow, 2017; Fletcher et al., 2018; Tandoc et al., 2017). In fact, scholars such as Vedel (2003) perceive digital or electronic democracy as being limited because of the quasi absence of content "moderators" or "mediators". Although Vedel believes mediators help reduce information overload, Morris (2002) and Bentivegna (2006) argue for the contrary. For them, content mediators eliminate direct forms of democracy by reinforcing "selective representations."

\section{The Future of Online Civic Engagement}

Despite the growing use of online communication to achieve political objectives, the likelihood of such platforms replacing conventional politics is yet to be determined. What is certain, however, is that individuals' civic engagement is likely to be determined by the kinds of information they already consume offline (Hindman, 2009; Howard, 2005). This includes joining online groups to engage with people we already interact with (Rice and Katz, 2004; Price and Capella, 2006). The whole idea of "online community" should be approached with caution because it is simply rooted on secondary relationships that shift with interests, spatio-temporal dynamics, and thus could dissolve at any time (Haddon, 2004).

Because online communication platforms offer more than just participating in political discussions, they also transform the whole notion of civic engagement, hence the preference in using "online civic engagement" in this article. Given the complexity associated with identifying specific forms of civic responsibility that are likely to be strengthened or weakened online, it is probably worth reconceptualizing the whole notion of civic duty. What is clear, however, is that the use of online platforms has shifted state-citizens relationships, including the manner in which elected officials interact or engage with their constituents (Morris, 2002). Precisely, there has been a gradual alleviation of bureaucratic barriers, which have served to increase interactivity between ordinary citizens and their elected representatives (Benson, 2001; Bentivegna, 2006). In other words, the concept of civic engagement has itself undergone transformative processes beyond the act of voting to include other communicative forms of civic responsibility. As McKinney et al. (2005, 6) note, "the driving force for democracy can [now] be found in individual citizens' many acts of joining, volunteering, serving, attending, meeting, participating, giving and perhaps most importantly, cooperating with others". 
Another important aspect of online civic engagement is associated with the rise of younger generations in grass-root and mainstream politics (Bakker and de Vreese, 2011; Owen, 2017). The core assumption here is that young citizens increasingly contribute in discussions and matters that concern various aspects of their lives without having to go through elected officials (Campbell and Kwak, 2010). Consequently, some have wondered "whether online campaigning, once hailed as the means to counter the steady decline in political participation, and rearrange existing power structures by empowering fringe parties and activists' organization of collective action, has an added value" (Vergeer $(2017,10)$.

Others also suggest the dynamics around online civic engagement can be understood by examining contemporary market-driven messaging practices, where political content is wittingly intertwined with the overall social media consumption and thereby rarely noticeable as a politicallyoriented message. Some have used "stealth media" to characterize such media that entice participation without being intrusive (Kim et al, 2018). That is, "a system that enables the deliberate operations of political campaigns with undisclosed sponsors/sources, furtive messaging of divisive issues, and imperceptible targeting" (ibid. p. 2).

Nonetheless, other scholars such as Vavreck and Lyenger (2011, 162) remind us that "understanding voters' reactions to commercials is fundamental to understanding the effectiveness of campaigns" in today's information-laden society. That is, while market-driven political communication provides political campaigners with the means to track people's attitudes/feelings about certain issues, people increasingly find political advertisements overwhelming and sometimes disparaging, particularly the younger generations. Other studies have also shown that people respond to media constructs disproportionately, and that the role of the elites in opinion formation is not as effective as it once was. This is probably why scholars such as Entman and Herbst (2000, 203) warn against confining public opinion to "comprehensive preferences of the majority". They write: "we cannot know public opinion definitely, via either surveys or other forms of evidence, which are at least as problematic and subject to framing" (p. 205).

Accordingly, Entman and Herbst (2000) believe that media's influence on politics depends on four forms of public opinion. That is, mass opinion (i.e. "the aggregation or summation of individual preferences as tabulated through opinion polls, referenda, or elections" p. 204), activated public opinion (i.e. "the opinions of engaged, informed, and organized citizens - those who are mobilizable during campaign periods and between elections as well" p. 205), latent public opinion (i.e. "where public opinion will 'end up' after a policy debate has progressed or what people truly feel beneath all the chaos and shifting opinion we see in the heat of democratic practice" p. 208), and perceived majorities (i.e. "the perceptions held by most observers, including journalists, politicians, and members of the public themselves, of where the majority of the public stands on an issue" p. 209).

In a sense, locating the causal mechanism that links online communication with one or several of these "forms" of opinion is still unclear. With increased personalization of socio-political realities, individual-centered forms of civic engagement have risen. As a consequence, it is difficult to create a common space for collective discourse to share meaningful policy options. In fact, some scholars such as Coleman (2005) have associated online communication platforms with symbolic forms of representative democracy because they are less likely to offer a genuine participatory process. Instead, they create distinctive needs, a characteristic of an individualistic approach to democracy. Overall, one challenge that researchers still wrestle with is how to measure the extent to which mediated political participation culminates into concrete forms of democratic engagement (i.e. civic activities likely to influence formal political decisions).

Recent studies have also reengaged with the influence of populism on civic engagement. Although there has been a strong interest on such topics since 2016, Bimber's (1998) work already 
documented how the rise of the Internet in the 1990s "restructure[d] political power in a populist direction" (p. 137). He writes:

What distinguishes the new populist enthusiasm for the Net is the additional idea that elites and political intermediaries will grow less important. In the populist vision not only will a mass audience be able to follow politics and express its views to government, but it will also be fundamentally less dependent on linkage organizations and group politics (Bimber, 1998, 138). Engesser, Fawzi and Larsson (2017) also note that populist actors progressively use online forums to streamline their strategies while increasing their "power, legitimacy, and mobilization" by "simplification, emotionalization, and negativity" (p. 1286). The success and/or receptivity of such messages are, however, still disputed. For instance, some believe that the likelihood of such messages having meaningful impact on someone's beliefs depends on individual's feeling of disfranchisement (Gerbaudo, 2014; Jansen, 2011). Put differently, attention-seeking attitude is what determines ideological resonance of populist content with varying segments of the population (Aalberg et al., 2017; Klinger and Svensson, 2015).

Finally, there are studies that examine the links between online civic engagement and emerging terrorist threats. That is, online platforms provide terrorist networks with the means to target and recruit populations feeling disenfranchised or excluded from the mainstream politics (Michael, 2013; Merolla and Zechmeister, 2009; Torres-Seriano, 2013). As Weimann (2014) observes, several reasons may explain why terrorist networks find online communication appealing: "First, these channels are by far the most popular with their intended audience, which allows terrorist organizations to be part of the mainstream. Second, social media channels are user-friendly, reliable, and free. Finally, social networking allows terrorists to reach out to their target audiences and virtually "knock on their doors" - in contrast to older models of websites in which terrorists had to wait for visitors to come to them" (p. 3). In essence, such appeals take different argumentative and persuasive forms such as "undifferentiated pitch" whenever "there is little serious opposition to the group in the audience's environment" (Gerwehr and Daly, 2006, 76). Overall, the future of online civic activity will depend on how citizens navigate these challenges while, at the same time, separating "objective facts" from what has become to be known as "fake news".

\section{Concluding Remarks}

While there is no doubt that online communication continues to have profound influence on political processes, the boundaries between emotional forms of appeal and "objective facts" have become blurred more than ever before. It is no longer clear whether online civic engagement is stimulated with increased/decreased political disinformation, populist narratives, or "post-truth" circumstances. This raises two important questions: to what extent do legitimate online news content matter in today's political opinion formation? Do "objective facts" have a role to play in shaping people's sense of civic responsibility? Conducting normative and empirical investigations along these lines would probably provide insights on how to map out and measure such tendencies across population groups and geopolitical regions. Recent studies by Fletcher et. al (2018) and Nielsen and Graves (2017) provide useful insights to this end. Another line of research could potentially focus on examining the relationship between conventional forms of civic engagement (e.g. making online donations to preferred candidates) and misconceived sense of civic duty as articulated by terrorist and jihadist organizations (e.g. making online donations to support terrorist activities). This would help rethink the notion of "civic duty" and locate some of the persuasive and argumentation schemes used by terrorist networks to incentivize violence as a form of civic duty and/or political participation. 


\section{References}

Aalberg, T. et al. (Eds.) (2017). Populist political communication in Europe. London: Routledge.

Aday, S. et al. (2012). Blogs and Bullets II New Media and Conflict after the Arab Spring. United States Institute of Peace.

Allcott, H.and Gentzkow, M. (2017). Social Media and Fake News in the 2016 Election. NBER Working Paper No. 23098. Retrieved from http://www.nber.org/papers/w23089

Anderson, L. (2011). Demystifying the Arab Spring. Foreign Affairs 90(3): 2-7.

Aström,J. and Karlsson M (2013). Blogging in the Shadow of Parties: Exploring Ideological Differences in Online Campaigning.Political Communication 30(3): 434-455.

Bakker, T.P. and De Vreese C.H. (2011). Good news for the future? Young people, Internet use, and political participation. Communication Research 38(4): 451-470.

Bennett,W.L.and Entman R.M. (Eds.) (2000). Mediated politics: Communication in the future of democracy. Cambridge University Press.

Benson, R. (2001). The Mediated Public Sphere: A Model for Cross-national Research. Working Paper Series, Berkeley, University of California. Retrieved from: http://www.irle.berkeley.edu/culture/papers/Benson01 08.pdf

Bentivegna, S. (2006). Rethinking politics in the world of ICTs. European Journal of Communication 21(3): 331-343.

Bimber, B. (1998). The Internet and Political Transformation: Populism, Community, and Accelerated Pluralism. Polity 31(1): 133-160.

Bimber,B. (2000). The Study of Information Technology and Civic Engagement, Political Communication 17(4): 329-333.

Böttcher, L., Woolley-Meza, O. and Brockmann, D. (2017). Temporal dynamics of online petitions. PLOS ONE 12(5): 1-12.

Billon, M., Lera-Lopez L.and Marco R. (2017). Patterns of Combined ICT Use and Innovation in the European Regions. Journal of Global Information Technology Management 20(1): 28-42.

Cammaerts, B.and Van Audenhove, L. (2005). Online political debate, unbounded citizenship, and the problematic nature of transitional public sphere. Political communication 22(2): 179-196.

Caldow, J. (1999). The Virtual Ballot Box: A Survey of Digital Democracy in Europe. Online: Institute for Electronic Government, IBM Corporation. Retrieved fromhttp://www01.ibm.com/industries/government/ieg/pdf/ddreport.pdf

Campbell, S.W.and Kwak N. (2010). Mobile communication and civic life: Linking patterns of use to civic and political engagement. Journal of Communication 60(3): 536-555.

Chen, W.and Wellman B. (2005). Minding the gaps: the digital divide and social inequality. In Blackwell Companion to Social Inequalities, eds. M. Romero and E. Margolis, 523-545. Oxford: Blackwell.

Coleman, S. (2005). New mediation and direct representation: reconceptualizing representation in the digital age. New Media \& Society 7(2): 177-198.

Dahlgren, P. (2000). The Internet and the democratization of civic culture. Political Communication 17: 335-340.

Dalrymple, K.E.and Scheufele, D.A. (2007). Finally informing the electorate? How the Internet got people thinking about presidential politics in 2004. Harvard International Journal of Press/Politics 12(3): 96-111.

DiMaggio, P. and Hargittai, E. (2001). From the 'Digital Divide' to digital inequality: studying Internet use as penetration increases. Work. Paper, Centre for Arts Cultural Policy Studies, Princeton University.

Earl, J. and Kimport, K. (2011). Digitally Enabled Social Change: Activism in the Internet Age. Cambridge: MIT Press. 
Engesser, S., Fawzi, N.and Larsson, A. (2017). Populist online communication: introduction to the special issue. Information, Communication \& Society 20(9): 1279-1292.

Entman, R.M.and Herbst, S. (2000). Reframing public opinion as we have known it. In Mediated politics: Communication in the future of democracy, eds. W.L. Bennett and R.M. Entman, 203-225. Cambridge University Press.

Fletcher, R. et al. (2018). Measuring the reach of "fake news" and online disinformation in Europe. Factsheet. Reuters Institute of Digital Journalism, Oxford

Gerbaudo, P. (2014). Populism 2.0. In Social media, politics and the state: Protests, revolutions, riots, crime and policing in the age of Facebook, Twitter and YouTube, eds. D. Trottier and C. Fuchs, 16-67. New York, NY: Routledge.

Graber, D.A. (2004). Mediated politics and citizenship in the twenty-first century. Annu. Rev. Psychol. 55: 545-71.

Gerwehr S.and Daly, S. (2006). Al-Qaida: Terrorist selection and recruitment. In The McGraw-Hill Homeland Security handbook, ed.D.G. Kamien, 73-89. Dubuque, IA: McGraw-Hill.

Haddon, L. (2004). Information and Communication Technologies in everyday life. Oxford: Berg.

Hayward, T. (1995). Info-Rich, Info-Poor: Access and Exchange in the Global Information Society. New Providence, NJ: K.G. Saur.

Helfer,L. and Van Aelst, P. (2016). What Makes Party Messages Fit for Reporting? An Experimental Study of Journalistic News Selection. Political Communication 33(1): 59-77.

Hindman, M. (2009). The myth of digital democracy. Princeton, NJ: Princeton University Press.

Howard, P.N. (2005). Deep democracy thin citizenship: The impact of digital media in political campaign strategy. Annals of the American Academy of Political \& Social Science 597: 153-170.

Jansen, R. (2011). Populist mobilization: A new theoretical approach to populism. Sociological Theory 29(2): 75-96.

Johnson, D.W. 2006. Congress online: bridging the gap between citizens and their (WORDS MISSING HERE). New York: Routledge.

Johnson, T.J. and Kaye, B.K. (2003). A boost or bust for democracy? How the Web influenced political attitudes and behaviours in the 1996 and 2000 presidential elections. Harvard International Journal of Press/Politics 8(3): 9-34.

Karshenas, M. and Stoneman, P. (1995). Technological diffusion. In Handbook of the economics of innovation and technological change, eds. M. Karshenas and P. Stoneman, 265-297. Oxford, UK: Blackwell.

Kim, M.Y. et al. (2018). The Stealth Media? Groups and Targets behind Divisive Issue Campaigns on Facebook. Political Communication 00(1): 1-27.

Klinger, U.and Svensson J. (2015). The emergence of network media logic in political communication: A theoretical approach. New Media \& Society 17(8): 1241-1257.

Krier, J.E. and Gillette C.P. (1985). The uneasy case for technological optimism. Michigan Law Review 405.

Manin, B. (1997). The Principles of Representative Government. Cambridge: Cambridge University Press.

Marx, L. (1994). The idea of 'Technology' and postmodern pessimism. In Technology, pessimism and postmodernity, eds.Y. Ezrahi, E. Mendelsohn and H. Segal, 11-28. Dordrecht: Kluwer.

Meraz, S. (2009). Is there an elite hold? Traditional media to social media agenda setting influence in blog networks. Journal of Computer Mediated Communication 14(3): 682-707.

Merolla, J.L. and Zechmeister E.J. (2009). Democracy at Risk: How Terrorist Threats Affect the Public. Chicago: University of Chicago Press.

McChesney, R.W. (1999). Rich media, poor democracy: communication politics in dubious times. Urbana: University of Illinois Press. 
McKinney, S.M. et al. (Eds.) (2005). Communicating politics: engaging the public in democratic life. New York: Peter Lang.

Michael, G. (2013). The New Media and the Rise of Exhortatory Terrorism. Strategic Studies Quarterly Spring 7(1): 40-68.

Michailidou, A. and Trenz, H.J. (2013). Mediatized representative politics in the European Union: towards audience democracy? Journal of European Public Policy 20: 260-277.

Moe, H. (2008). Dissemination and dialogue in the public sphere: a case for public service media online. Media, Culture \&o Society 30(3): 319-336.

Nielsen, R. and Graves L. (2017). 'News You Don't Believe': Audience Perspectives on Fake News. Factsheet. Reuters Institute of Digital Journalism, Oxford.

OECD. (2011). Regions and innovation policy. Geneva, Switzerland: OECD.

OECD. (2015). The innovation imperative: Contributing to productivity, growth and well-being. Geneva, Switzerland: OECD.

Owen, D. (2017). New Media and Political Campaigns. New York: Oxford University Press.

Park,H.M. and Perry,J.L. (2008). Do campaign websites really matter in electoral civic engagement? Empirical evidence from the 2004 post-election Internet tracking survey. Social Science Computer Review 26(3): 190-212.

Poor, N. (2006). Mechanisms of an Online Public Sphere: the Website Slashdot. Journal of ComputerMediated Communication 10(2): article 4, retrieved from https://onlinelibrary.wiley.com/doi/full/10.1111/j.1083-6101.2005.tb00241.x

Price, V.and Capella, J.N. (2006). Normative and informational influences in online political discussions. Communication Theory 16(1): 47-74.

Rice, R.E.and Katz J.E. (2004). The Internet and political involvement in 1996 and 2000. In Society online: The Internet context, eds. P. N. Howard and S. Jones, 103-120. London: Sage Publications.

Tandoc Jr., E.C. (2017). Defining 'Fake News': A Typology of Scholarly Definitions, Digital Journalism 5 (7): $1-17$.

Tewksbury, D. (2006). Exposure to the newer media in a presidential primary campaign. Political Communication 23(3): 313-332.

Torres-Seriano, M.R. (2013). The Dynamics of Creation, Evolution, and Disappearance of Terrorist Internet Forums. International Journal of Conflict and Violence 7(1): 164-178.

Trammell, K.D. et al. (2006). Evolution of online campaigning: Increasing interactivity in candidate Web sites and blogs through text and technical features. Mass Communication \&

Society, 9(1): 22-44.

Van Deursen, A. and Van Dijk J. (2014). The digital divide shifts to differences in usage. New Media \& Society 16(3): 507-526.

Vedel, T. (2003). Internet et les pratiques politiques. In La communication politique. Etat des savoirs, enjeux et perspectives, ed. A.M. Gingras, 189-214. Ste-Foy, QC : Presse de l'université du Québec.

Vergeer, M. (2013). Politics, elections and online campaigning: Past, present... and a peek into the future. New Media \& Society 15(1): 9-17.

Weimann, G. (2014). New Terrorism and New Media. Commons Lab of the Woodrow Wilson International Center for Scholars, Retrieved from http://www.wilsoncenter.org/publication/new-terrorismand-new-media

Wolfsfeld, G., Segev E. and Sheafer T. (2013). Social Media and the Arab Spring: Politics Comes First. The International Journal of Press/Politics 18(2): 115-137.

Wresch, W. (1996). Disconnected: Haves and have-nots in the information age. Rutgers University Press. 